\title{
PERSPECTIVAS HORIZONTAIS PARA O CURRÍCULO: CONTRIBUIÇÕES TEÓRICAS E METODOLÓGICAS PARA A EDUCAÇÃO
}

\author{
HORIZONTAL PERSPECTIVES FOR THE CURRICULUM:THEORETICAL AND \\ METHODOLOGICAL CONTRIBUTIONSTO EDUCATION
PERSPECTIVAS HORIZONTALES PARA EL CURRÍCULO: CONTRIBUCIONES TEÓRICASY METODOLÓGICAS PARA LA EDUCACIÓN

\author{
Marcus Alexandre de Pádua Cavalcanti* \\ marcus_nathan1203@hotmail.com \\ Sandramor do Amaral Ferreira ** \\ sandramoramaral@gmail.com \\ * Universidade Federal do Rio de Janeiro, Rio de Janeiro, RJ - Brasil
** Serviço Nacional de Aprendizagem Industrial , Serviço Nacional de Aprendizagem Comercial, Rio de Janeiro, RJ - Brasil
}

\begin{abstract}
Resumo
O presente trabalho pretende apresentar algumas questões acerca do currículo por meio de uma abordagem horizontal. Nosso objetivo é discorrer acerca de tal perspectiva e realizar algumas aproximações com o campo do currículo em por meio de um modelo rizomático que possibilita pensar o currículo para além de um arranjo de disciplinas. Desse modo, procuraremos destacar que as produções curriculares modernas apresentam uma concepção de conhecimento que tende a reforçar a concepção essencialista de que é possível atingir conhecimento científico universal, capaz de fornecer verdades sobre o mundo. Em oposição aos paradigmas universalistas, propomos que um currículo horizontal tenderia a enfatizar as noções de diferença, promovendo a heterogeneidade, privilegiando a pluralidade e a diversidade dos saberes produzidos, criando conexões entre os diversos saberes. Para isso, buscamos na perspectiva rizomática uma nova forma de comportamento por meio de múltiplas aberturas que recusam a imposição de um conhecimento dado a priori, compreendido como verdade absoluta.
\end{abstract}

Palavras-chave: Método horizontal; Currículo; Rizoma.

\begin{abstract}
The objective is to discuss this perspective and to make some approximations with the field of curriculum in a rhizomatic model that makes it possible to think about the curriculum in addition to an arrangement of disciplines. In this way, we will try to emphasize that modern curricular productions present a conception of knowledge that tends to reinforce the essentialist conception that it is possible to reach universal scientific knowledge capable of providing truths about the world. In opposition to the universalist paradigms, we propose that a horizontal curriculum would tend to emphasize the notions of difference, promoting heterogeneity, privileging the plurality and diversity of the knowledge produced, creating connections between the different knowledge. To this end, we seek in the rhizomatic perspective a new form of behavior through multiple openings that refuse to impose a priori knowledge, understood as absolute truth.
\end{abstract}

Keywords: Horizontal method; Curriculum; Rhizome.

\section{Resumen}

El objetivo es discurrir acerca de tal perspectiva y realizar algunas aproximaciones con el campo del currículo en por medio de un modelo rizomático que posibilita pensar el currículo más allá de un arreglo de disciplinas. De este modo, procuraremos destacar que las producciones curriculares modernas presentan una concepción de conocimiento que tiende a reforzar la concepción esencialista de que es posible alcanzar conocimiento científico universal, capaz de proporcionar verdades sobre el mundo. En oposición a los paradigmas universalistas, proponemos que un currículo horizontal tendería a enfatizar las nociones de diferencia, promoviendo la heterogeneidad, privilegiando la pluralidad y la diversidad de los saberes producidos, creando conexiones entre los diversos saberes. Para ello, buscamos en la perspectiva rizomática una nueva forma de comportamiento por medio de múltiples aberturas que rechazan la imposición de un conocimiento dado a priori, comprendido como verdad absoluta.

Palabras clave: Método horizontal; Currículo; Rizoma. 


\section{INTRODUÇÃO}

A preocupação com o currículo faz-se notar, com constância, nas políticas, nas práticas e nas pesquisas da área da educação. No que se refere às teorias de currículo, novos temas, novos problemas e novas teorizações têm tentado responder aos persistentes e aos desafios contemporâneos enfrentados por todos os que participam das decisões e práticas curriculares e se esforçam por melhor compreendê-las e por melhor atuar. Pode-se afirmar que o campo do currículo, atualmente, revela-se dinâmico, flexível e atento aos desenvolvimentos de outros campos. O presente trabalho pretende apresentar algumas questões acerca do currículo por meio da Teorização Pós-crítica do currículo com Veiga Netto (2002), Silvio Gallo (2003, 2007), Tomaz Tadeu da Silva (1994, 2004), Macedo (2004), que tecem discussões relevantes sobre a diferença. Utilizaremos ainda as contribuições do pensamento pós-colonial de Homi Bhabha (1998) e de pensadores pós-estruturalistas como Michel Foucault (1986) e Gilles Deleuze (1995) que tecem discussões relevantes sobre as relações de poder e o pensamento da diferença.

Segundo Costa (2013, p.8), no campo da pesquisa em educação,

O pensamento da diferença nos chega pelas vias dos estudos do currículo e nos interpõem difíceis desafios: imprimir um duplo exercício ao pensar da crítica mediante as 'imagens dogmáticas do pensamento' que imobilizam o acontecimento e a singularidade dos fenômenos.

As questões que ora nos instigam são: $\mathrm{O}$ que se entende por uma metodologia horizontal que privilegie a diferença no campo curricular? Por meio de quais desdobramentos ou ressonâncias é possível pensar um currículo na perspectiva da diferença?

Essas questões nos parecem pertinentes, pois nos vemos movidos pelo desejo de respostas adequadas a atual realidade curricular que não mais comporta o atual modelo disciplinar. Desse modo, buscamos outras possibilidades de pensar o currículo, possibilidades essas que ensejam o entendimento dos saberes, das suas tessituras e dos modos como está encerrado/consagrado o conhecimento cientifico, afastando, dessa forma, a possibilidade de outros modos de concebê-lo. É sob esta perspectiva que pretendemos empreender as discussões propostas neste artigo.

Nesse sentido, pensar a o currículo a partir de outras bases, é um desafio, entre tantos, a que nos propomos. Com isso não queremos dizer que estamos lançando fora todo um arcabouço teórico que foi construído ao longo da história, ou mesmo desconsiderando a seriedade com que incontáveis trabalhos acadêmicos de renomados pesquisadores foram e estão sendo construídos. Trata-se sim de uma escolha em fazer alguns deslocamentos e aproximações do olhar a outras questões que ora nos instigam e nos inquietam. 
A partir dos escritos e das discussões pós-estruturalistas e de estudos filosóficos da diferença no campo curricular para a educação passamos a pensar no currículo entendendo-o como um campo de saber que não é dado e sim construído, promovendo a heterogeneidade, criando conexões entre os diversos saberes e propondo uma forma de comportamento por meio de múltiplas aberturas que recusa a imposição de um conhecimento dado a priori, compreendido como verdade absoluta.

\section{O CURRÍCULO: PERSPECTIVAS HORIZONTAIS PARA O CONHECIMENTO}

O currículo escolar foi influenciado pelo conceito de ciência moderna, ou seja, prescrito de forma linear, universal e formal. Esse currículo se fundamenta nos pressupostos dos avanços científicos e tecnológicos, que legitimam o status das ciências naturais, desqualificando toda e qualquer relação e conexão com exterior (VEIGA NETO, 2002).

De acordo com Veiga Neto (2002) os currículos tradicionais caracterizam-se por apresentar uma ordem vertical e disciplinar, que constitui o eixo de todo o processo educativo. Nesta perspectiva de entendimento, pode-se dizer que a educação institucionalizada e as instituições educativas são produtos da modernidade e emergem nas sociedades das disciplinas (FOUCAULT, 1986).

Veiga Neto (2002) afirma que como consequência disso, é possível perceber uma geometrização de saberes e do mundo como um todo. $\mathrm{O}$ autor amplia a visão determinista e reprodutiva do currículo, presente nos estudos do campo, ao analisar a sua construção de maneira imanente. Desta forma, considera as relações sociais e curriculares como extrínsecas, cujos entrelaçamentos se confundem, pois o currículo não é somente produzido pelo social.

O currículo é pensado e funciona como uma estrutura classificatório-disciplinar; por isso ele é estruturante. E, por ter uma estrutura disciplinar, ele funciona como um estruturante disciplinador. A consequiência disso é que ele gera, no âmbito em que atua, o entendimento não apenas de que os saberes têm (naturalmente) uma distribuição disciplinar que é espacial, mas também de que o próprio mundo tem essa, e apenas essa, espacialidade. Na medida em que ele se estabelece disciplinarmente e na medida em que a sociedade moderna é uma sociedade em que os indivíduos mais e mais se individualizam e se autodisciplinam (como nos mostrou Michel Foucault) (VEIGA NETO, 2002, p.171)

Com essa afirmação, o autor nos mostra como o currículo escolar foi relevante no projeto da Modernidade. Dessa forma, o currículo de ciências acaba sendo fortemente influenciado por uma epistemologia internalista de um conhecimento cientifico pensado como neutro que busca solucionar os problemas por meio de uma verdade absoluta da natureza, ou seja, a ciência busca, assim, em seu 
processo se hegemonizar como única referencia e substituir sistemas, práticas cotidianas pela crença na objetividade.

Tomaz Tadeu da Silva (2004) explicita que a vertente pós-estruturalista assume a crítica ao modelo linear de currículo que prescreve uma trajetória de aprendizagem baseada em uma concepção essencialista dos conteúdos que teriam a pretensao de atingir conhecimento científico universal, capaz de fornecer verdades sobre o mundo. Em oposição aos paradigmas universalistas, o autor propõe uma concepção pós-estrturalista de currículo que tenderia a enfatizar as noções de diferença, promovendo a heterogeneidade, privilegiando a pluralidade e a diversidade dos conhecimentos, produzidos conexões entre os mesmos, buscando uma perspectiva rizomática e propondo uma forma de comportamento por meio de múltiplas aberturas que recusa a imposição de um conhecimento dado a priori, compreendido como verdade absoluta.

Tomaz Tadeu da Silva (2004), baseando-se em Deleuze e Guattari, defende um novo estilo na escrita educacional. O autor parte para uma nova estilística que supere o estilo de neutralidade e cientificidade herdada da modernidade. Desse modo, o autor procura compreender a produção do currículo como a construção de "um mapa, sempre desmontável, conectável, reversível, suscetível de receber modificações constantemente” (DELEUZE; GUATTARI, 1995, p.33).

A partir desta perspectiva, Gallo (2003) afirma que o currículo tradicional pode ser pensado como uma grande árvore, cujas características morfológicas, de toda árvore de grande porte, possuem raízes maiores, galhos abrangentes e um caule firme e espesso, assim nos diz Gallo:

O paradigma arborescente implica numa hierarquização do saber, como forma de mediatizar e regular o fluxo de informações pelos caminhos internos da árvore do conhecimento. O paradigma arborescente representa uma concepção mecânica do conhecimento e da realidade, reproduzindo a fragmentação cartesiana do saber resultado das concepções cientificas (GALLO, 2003, p. 88 e 89).

Desse modo, seria possível perceber que a relação do currículo com fatores externos ainda é pouco explorada em âmbito escolar, isto é, os currículos elegem a ciência como uma necessidade humana, mas pouco se problematizam seus feitos, seus modos. Não há uma "postura critica em relação aos conhecimentos científicos e tecnológicos", mas quase sempre uma aceitação (MACEDO, 2004, p.35)

Nessa perspectiva, o currículo passa a ser visto como uma forma de legitimar conhecimentos, isto é, só é aceito um tipo de conhecimento se este for cientificamente comprovado. Mais ainda, os conhecimentos científicos chegam às salas de aulas como resultado de um conhecimento cumulativo, 
regular, linear, e homogêneo. Paralelamente, o ensino proposto pelo currículo de ciências também é tido como universal e internalista. Professores e alunos são postos no processo educacional como indivíduos neutros. Assim, a neutralidade é imposta pelo professor quando ele simplesmente transmite o que deve ser ensinado, da mesma forma, é neutro o aluno que apenas assimila o que é transmitido. Dessa forma, o currículo permanece fixado como um grande eixo de onde se originam normas, técnicas e praticas do que se deva ensinar e como se deve aprender (GALLO, 2007, p. 291).

Gallo (2007), em sua obra Deleuze e a Educação, propõe um modelo de currículo rizomático que

Reuniria em seu eixo a totalidade do conhecimento ela começa a desenvolver galhos das mais diversas especializações que, embora mantenham suas estreitas ligações com o tronco - apontam para as mais diversas direções, não guardando entre si outras ligações que não seja o seu "tronco comum". Embora não consigam, no contexto deste paradigma, relacionar-se entre si (GALLO, 2003, p. 89).

Contrapondo-se a isso é possível pensar uma espécie de modelo rizomático de currículo que não estaria determinado por pontos e posições a priori, isto é, estaria além do pensamento arborescente. Como afirma Deleuze (1995, p. 31).

Diferentemente das árvores ou de suas raízes, o rizoma conecta um ponto qualquer com outro ponto qualquer, e cada um de seus traços não remete necessariamente a traços de mesma natureza, ele põe em jogo regimes de signos muito diferentes, inclusive estados de não-signos. O rizoma não se deixa reduzir nem ao Uno nem ao múltiplo... Ele não é feito de unidades, mas de dimensões, ou antes, de direções movediças. Não tem começo nem fim, mas sempre um meio pelo qual ele cresce e transborda. Ele constitui multiplicidades.

Silvio Gallo (2003) desloca o conceito de rizoma para ser pensado na educação. Nessa perspectiva o currículo escolar deveria ser pensado como um elemento que produz movimentos, conexões, mais ainda, que está composto numa multiplicidade (escola, alunos, professores, pais) que possibilita outras multiplicidades nos corpos daqueles que o constitui, antes mesmo de ser percebido como algo que organiza disciplinas pura e simplesmente, por exemplo. E esses movimentos dinamizamno. O currículo escolar passa a se organizar a partir das conexões, das relações, das variações, que possibilitam uma integração entre as disciplinas, as especialidades, sem uma filiação ou um eixo organizador único, apontando as direções que se tem que seguir, mas possibilidades, caminhos e todos conectados entre si. 


\section{O RIZOMA: UMA PROPOSTA HORIZONTAL PARA O CURRÍCULO}

De acordo com Gallo (2007), o modelo de currículo rizomático rompe com um modelo arborescente do currículo e introduz um pensamento que se difere da concepção mecânica do conhecimento e da realidade, reproduzindo a fragmentação cartesiana do saber, resultado das concepções científicas modernas. Gallo $(2007$, p.301) cita como exemplo a "ecologia que faz intersecção com diversos campos como a Biologia, a Geografia, a Ciência Política, a Sociologia e mesmo a Filosofia" O modelo de currículo rizomático em ciências nos remete para a idéia de multiplicidade. Levando em consideração os fluxos, as interconexões existentes entre as diferentes áreas do conhecimento científico, elementos que remetem uns aos outros e mesmo para fora do próprio conjunto, "pois o rizoma, sempre aberto, faz proliferar pensamentos" (Idem).

Para a perspectiva de currículo rizomático em ciências podemos afirmar que este pode ser ou estar conectado a qualquer outro ponto, sem obedecer a uma linha determinada. Nesse sentido, utlizamos o conceito de rizoma de Deleuze e Guattari (1995) para e relacioná-lo com o currículo em ciências.

De acordo com Deleuze e Guattari (1995) o rizoma é regido por seis princípios, são eles:

$1^{\circ}$ e $2^{\circ}$ - Princípios de conexão e heterogeneidade: "qualquer ponto do rizoma pode ser conectado a qualquer outro e deve sê-lo" (p. 15). A metáfora da árvore ou raiz remete-se a centros de poder, à hierarquia, estruturas e relações binárias e biunívocas, em contrapartida os acessos de um rizoma são múltiplos, fazendo com que ele não tenha centro e que ele tome qualquer direção e forma. Não existe forma previa, nem determinismos, as conexões são feitas por contágio ou contato.

$3^{\circ}$ - Princípio de multiplicidade: os autores preferem usar a expressão multiplicidade ao invés de múltiplo - cuja ausência de unidade seria sua característica principal. As multiplicidades são linhas, que de modo algum possuem pontos fixos. Além disso, só existe uma unidade ou identidade na multiplicidade quando se elabora, ou processos de subjetivação, ou processos de significação - assim sendo, dissimulam-se essências. Assim, se de um lado a unidade cria uma sobrecodificação da multiplicidade, produzindo uma dimensão vazia de sentido; de outro o rizoma produziria um plano de consistência que permanece sempre em expansão e movimento, o que não possibilita que ele seja capturado pela sobrecodificação. "As multiplicidades se definem pelo fora: pela linha abstrata, linha de fuga ou desterritorialização segundo a qual elas mudam de natureza ao se conectarem às outras" (DELEUZE; GUATTARI, 1985, p.18).

$4^{\circ}$ - Princípio de ruptura a-significante: Todo rizoma compreende linhas de segmentaridade, que o caracterizam como estratificado, territorializado e com o significado organizado. Contudo, tais linhas podem ser rompidas e difundidas umas nas outras, reaproximando-se, e até reconstituindo o conjunto 
original. Considerando esse dualismo, ele também possui uma característica de desterritorialização. Ele não tem um começo ou um fim específico, mas um meio no qual ele cresce e transborda (DELEUZE; GUATTARI, 1995).

$5^{\circ}$ e $6^{\circ}$ - Princípio de cartografia e de decalcomania: $\mathrm{O}$ método cartográfico vai funcionar como o instrumento que vai fotografar o acontecimento, tal cartografia nos mostra que ele possui entradas múltiplas. O rizoma pode ser acessado de qualquer ponto, possibilitando daí remeter a quaisquer outros em seu território. O paradigma arborescente remete ao mesmo, pois toda a lógica da árvore é uma lógica da cópia, da reprodução. O rizoma não se baseia em nenhum modelo estrutural ou gerativo, uma vez que possui caráter aberto, conectável e suscetível de receber modificações. Por isso ele é um sistema que não possui hierarquia e significante definido (DELEUZE; GUATTARI, 1995).

Se o conhecimento for pensado como rizoma e não como árvore, as disciplinas já não seriam gavetas que não se comunicam, mas tenderiam a soar como linhas que se misturam - teia de possibilidades, de conexões, multiplicidade de nós, de interconexões. A noção de rizoma é contributiva principalmente nas discussões quanto a natureza, abrangência da área e suas inter-relações com outros domínios. Além disso, o conceito de rizoma traz á tona as reflexões acerca da organização do conhecimento, pondo em choque as estruturas rígidas e planificadas de representação, assim como questiona os aspectos hierárquicos e unilaterais das mesmas (GALLO, 1994)

Nesse sentido, Gallo (2007) afirma que o fora se faz presente mais do que o que esta dentro. $\mathrm{Ou}$ seja, a grade curricular do ensino conheceria seus acontecimentos mediante suas determinações históricas e singulares - de conceitos, teorias, leis - desterritorializando-se a partir de suas conexões. Assim, uma linha que constitui o currículo em ciências "pode ser quebrada e conectada a outro lugar qualquer" (DELEUZE, 1995, p. 17).

\section{O CURRÍCULO COMO ENTRE-LUGAR NA EDUCAÇÃO}

Ao propor uma perspectiva horizontal para o currículo, acreditamos que o conceito de entre-lugar de Bhabha (2008) torna-se fundamental para inovação pensarmos o cotidiano na educação. Pensar o currículo como entre-lugar é percebê-lo como processo em permanente negociação, promovendo discursos e práticas para além de supostas noções universais e que também une dois aspectos - o do fazer e o do saber - comumente dicotomizados pela ciência moderna. É pensá-lo como redes tecidas de conversações e significados que problematizam e trazem consigo relações e processos de criação curricular onde são tensionados aspectos ligados a política, a ética, a estética em redes outras de conhecimentos. 
As noções dos currículos de entre-lugar são relacionadas à visão e ao modo como os sujeitos praticantes posicionam-se diante das relações de poder e como realizam táticas para seu empoderamento, mesmo que estes movimentos estejam invisibilizados e/ou ignorados pelos saberes hegemônicos. Acreditamos, assim, que, por se tratar por espaços outros e legítimos de produção de encontros, a busca e o entendimento dos entre-lugares na tessitura curricular pode auxiliar na construção das potências tecidas coletivamente pelos sujeitos praticantes. "Um entre-lugar em que o novo surge como ato insurgente de tradução cultural" (BHABHA, 2008, p. 27).

A concepção de entre-lugares contribui para que possamos compreender os processos de trocas culturais, que envolvem relações de poder. Permite pensar em como múltiplos poderes se entrelaçam tornando tênues as fronteiras entre coleções culturais distintas. Nessa perspectiva, o encontro com o novo não é mera reprodução ou continuidade de passado e presente. Ele renova e reinterpreta o passado, reconfigurando como um entre-lugar contingente, que inova, interrompe e interpela a atuação do presente. O horizonte hermenêutico e de intervenção social a partir da possibilidade de negociação da cultura, ao invés de sua negação, comum nas posições dicotômicas torna possível conceber a articulação de elementos antagônicos ou contraditórios (BHABHA, 2008).

Desse modo, pensamos ser necessário considerar os entre-lugares dos currículos como dimensões de intensificação de encontros onde se praticam movimentos de negociação e interpenetração permanente de proposições, entendimentos e possibilidades emancipatórias. Perscrutar os entre-lugares da diferença pode nos levar a descobrir um pouco mais sobre os processos de (in)visibilização da diferença no campo curricular.

\section{CONSIDERAÇÕES FINAIS}

A partir dos escritos e das discussões pós-estruturalistas, da Teorização Pós-crítica do currículo e do pós-colonialismo buscamos nesse texto propor um currículo compreendendo-o como um campo de saber que não é dado e sim construído. Ao promover a heterogeneidade, criando conexões entre os diversos saberes propomos uma abordagem horizontal que oferece uma forma de comportamento por meio de múltiplas aberturas que recusa a imposição de um conhecimento dado a priori, compreendido como verdade absoluta.

Ao contrário de uma estrutura que se define por um conjunto de pontos e de posições de relações binárias entre estes pontos e de relações biunívocas entre estas posições, a abordagem horizontal é apenas constituído por linhas. Desse modo, a essa proposta possibilita as mais diversas articulações entre 
os mais variados campos de saber, pois essa abordagem propõe um sistema aberto de multiplicidade sem pontos e posições fixas, permitindo assim movimentos de invenção e criação.

Desta maneira, acreditamos que a adoção de uma abordagem horizontal curricular significa, ao mesmo tempo, uma nova proposta do próprio conhecimento para integrações entre os vários saberes existentes e uma produção que promove a abertura entre o conhecimento que se desvincula da tentativa de homogeneização, de modelo, de uno, para o reconhecimento do múltiplo e da diferença.

\section{Referências}

BНАВНА, H. O local da Cultura. Belo Horizonte: Ed. UFMG, 2007.

DELEUZE, Gilles; GUATTARI, Felix. Mil Platôs: capitalismo e esquizofrenia. Vol.1. Ed: 34. Rio de Janeiro. 1995.

FOUCAULT, Michel. Microfísica do poder. Rio de Janeiro, Ed. Graal, 1984.

GALlO, Silvio. Deleuze e a Educação. 2 ed. Belo Horizonte: Autêntica, 2007.

MACEDO, Elizabeth. Ciência, Tecnologia e Desenvolvimento: Uma visão cultural do currículo de ciências. In: LOPES, A. C; MACEDO, E. (Org.). O currículo de ciências em debate. Ed: Papirus. Campinas, 2004.

SILVA, Tomaz Tadeu (Org.). O sujeito da educação: Estudos foucaultianos. Petrópolis: Vozes, 1994.

A filosofia de Deleuze e o Currículo. Faculdade de Artes Visuais. 2004.

Currículo: pensar, sentir e diferir. Rio de Janeiro: DP\&A, 2004.

VEIGA NETO, Alfredo. De Geometrias, Currículo e Diferenças IN: Educação e Sociedade, Dossiê Diferenças. Campinas: $n^{\circ} 79,2002$. 
Recebido em: 23/10/2017

Aceito em: 12/11/2017

Endereço para correspondência:

Nome: Marcus Alexandre de Pádua Cavalcanti

Email: marcus_nathan1203@hotmail.com

Esta obra está licenciada com uma Licença Creative

Commons Atribuição 4.0 Internacional. 